\title{
Limbic Encephalitis: Under-Recognition of Voltage-Gated Potassium Channel Antibodies
}

\author{
S.R. Irani ${ }^{\mathrm{a}} \quad$ K. Fukushima $^{\mathrm{b}} \quad$ M. Yazaki ${ }^{\mathrm{b}} \quad$ A. Vincent $^{\mathrm{a}}$

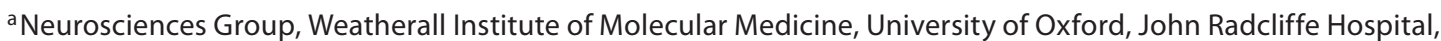

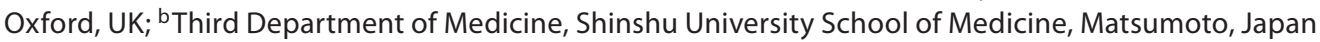

Dear Sir,

Fukushima et al. [1] reported a case of steroid-responsive limbic encephalitis (LE) without clear aetiology. Their patient presented with generalised and complex partial seizures, amnesia, hyponatraemia and bilateral medial temporal lobe high signal on fluid-attenuated inversion recovery magnetic resonance images (MRI). This symptom myriad is best described within the rubric of LE. LE is traditionally considered a paraneoplastic phenomenon; hence the appropriately intensive search for occult malignancy by Fukushima et al. [1]. However, recently voltage-gated potassium channel antibodies (VGKC-Ab) have been shown to be a more reversible, infrequently malignant cause of LE [2].

The patient described by Fukushima et al. [1] also demonstrated prominent hormonal abnormalities, including the syndrome of inappropriate $\mathrm{ADH}$ (SIADH) and impaired thyrotropin-releasing hormone secretion. In keeping with this, previous descriptions of VGKC-Ab-associated LE have reported SIADH (in $80 \%$ of cases), significant appetite and weight gain (in 30\%) and occasional abnormal thyroid function. However, SIADH is not a specific feature for VGKC-Ab-associated LE, since $\mathrm{ADH}$ is secreted from some small cell lung cancers, and $1 \%$ of all small cell lung cancer is associated with anti-Hu paraneoplastic LE.

Since the report of Fukushima et al. [1], we have shown the serum of their patient to be strongly positive for VGKC-Ab $(2,354$ $\mathrm{pM})$. The antibody titre decreased during treatment to $901 \mathrm{pm}$. This test is a radioimmunoassay utilising the binding of ${ }^{125}$ I-radiolabelled $\alpha$-dendrotoxin to specific potassium channels. The results are expressed as picomoles of ${ }^{125} \mathrm{I}$-dendrotoxin-VGKC-binding sites per litre of serum [3]. Results below 100 pm are considered negative, although we have found $5 \%$ of elderly subjects to have a titre between 100 and $400 \mathrm{pm}$ [2].

Previously, we have demonstrated the presence of VGKC-Ab in two patients initially considered to have Hashimoto's encephalopathy [3]. Hashimoto's encephalopathy, in contrast to VGKC-Ab LE, often presents with prominent stroke-like episodes and frequent tremor. However, there is also some overlap: Hashimoto's encephalopathy patients often have neuropsychiatric presentations, sleep disturbances, can show medial temporal lobe MRI abnormalities [4], demonstrate thyroid hormone abnormalities and often show an excellent steroid response.

These cases illustrate the need to consider VGKC-Ab-associated LE in the dif- ferential diagnosis of confusion with seizures. It is evident that the VGKC-Ab-positive subgroup of LE is under-recognised. While the clinical distinction between subtypes of such 'limbic encephalitis' is complex, neuroendocrine abnormalities may provide a clue as to the likely, often non-paraneoplastic, aetiology.

\section{References}

1 Fukushima K, Yasaki M, Kaneko K, Fushimi T, Yamamoto K, Hashimoto T, Oguchi K, Ikeda S: Nonparaneoplastic, nonherpetic limbic encephalitis with severe episodic hypothermia: a case report. Eur Neurol 2005; 54:170-174.

2 Vincent A, Buckley C, Schott JM, Baker I, Dewar BK, Detert N, Clover L, Parkinson A, Bien CG, Omer S, Lang B, Rossor MN, Palace $\mathrm{J}$ : Potassium channel antibody-associated encephalopathy: a potentially immunotherapy-responsive form of limbic encephalitis. Brain 2004;127:701-712.

3 McKnight K, Jiang Y, Hart Y, Cavey A, Wroe S, Blank M, Shoenfeld Y, Vincent A, Palace J, Lang B: Serum antibodies in epilepsy and seizure-associated disorders. Neurology 2005;65:1730-1736.

4 McCabe DJ, Burke T, Connolly S, Hutchinson $\mathrm{M}$ : Amnesic syndrome with bilateral mesial temporal lobe involvement in Hashimoto's encephalopathy. Neurology 2000;54: 737-739.

\section{KARGER}

Fax +4161306 1234 E-Mail karger@karger.ch www.karger.com
(C) 2007 S. Karger AG, Basel 0014-3022/07/0583-0184\$23.50/0

Accessible online at: www.karger.com/ene
Dr. Sarosh Irani

Neurosciences Group, The Weatherall Institute of Molecular Medicine

University of Oxford, John Radcliffe Hospital

Oxford OX3 9DS (UK)

Tel. +44 186522 2327, Fax +44186522 2402, E-Mail saroshirani@doctors.net.uk 